\title{
LA HISTORIA COMO FICGIÓN Y LA FICCIÓN COMO HISTORIA. VARGAS LLOSA Y MAYTA*
}

La última novela de Mario Vargas Llosa, Historia de Mayta ha suscitado en la crítica peruana algunas objeciones - unas más bien totalizantes, otras de detalle- que se dirigen a aspectos temático-ideológicos o a la técnica narrativa².

Pienso que tanto los comentarios adversos como las "defensas" de los más incondicionales admiradores del autor no reconocen debidamente el proyecto que el texto realiza: un proyecto que se anuncia y se actualiza simultáneamente, que se descubre con afán exhibicionista en el discurso narrativo y a la vez se oculta tras él como un componente más de la ficción. A la radical ambigüedad de un discurso que cumple la promesa de contar una historia en el acto mismo de prometerla, se le suman - como escollo o incentivo adicional según el gusto del lector- las reiteradas reflexiones de un narrador-autor omnipresente, "demasiado visible", y cuyo estatuto ficcional es tan poco obvio como el de su relato y el de los referentes del relato.

Mi impresión es que Historia de Mayta es no sólo ni en primer lugar una obra inspirada en la más reciente historia de la violencia en el Perú, sino además - y quizás antes que cualquier otra cosa- una novela "poetológica" cuyo autor presenta, en forma

* Este trabajo es una versión muy ampliada de una ponencia presentada en el IX Congreso de la Asociación Internacional de Hispanistas, celebrado en Berlín en agosto de 1986.

${ }^{1}$ Seix Barral, Barcelona, 1984. Todas las citas de la novela que aparecen en el texto se refieren a esta edición.

${ }^{2}$ Los aspectos polémicos de este trabajo se relacionan exclusivamente con las opiniones que sobre la obra han aparecido en el Perú y que he recogido con la mayor exhaustividad posible. 
de ficción novelesca, sus propias concepciones e ideales acerca de la ficción literaria.

Semejante idea no es, por cierto, una gran novedad. La mayoría de los críticos -y entre ellos el propio novelista, como exégeta de su obra - han señalado, con variado énfasis y variada intención, la preeminencia que ha ido adquiriendo en su universo temático el acto de fabular, la relación dialéctica entre lo vivido y lo fantaseado y, especialmente, el proceso de construcción de un mundo autónomo a partir de la experiencia y la imaginación. Sin embargo, el reconocimiento de este hecho no siempre ha ido acompañado de una evaluación desapasionada: para unos Historia de Mayta es una novela fallida, en la que la ficción no llega a cuajar por la constante e importuna confrontación de lo ficticio con lo real y por el peso de una ideología demasiado explícita ${ }^{3}$; para otros se trata de una visión parcializada y ambigua de la historia peruana, en la que las frecuentes declaraciones del narrador sobre su actividad fabuladora son, además de un error de construcción, una manera bastante ingenua de camuflar las verdaderas opiniones del autor sobre el origen de la violencia político-social en el Perú, así como sus hepáticas críticas a grupos políticos y personas particulares y su desesperanza - "burguesa"- ante el. futuro ${ }^{4}$.

Es preciso admitir que Vargas Llosa es hasta cierto punto responsable de que su novela haya suscitado juicios que, como los precedentes, no llegan a aceptar del todo la función central, estructuradora, que cumple en ella la reflexión sobre el proceso de novelar. Él mismo, tal vez bajo la presión de la avidez de actualidades de los periodistas que en España y en el Perú lo han entrevistado a propósito de la presentación de su libro, ha hecho demasiado hincapié en el contenido ético-político de la historia del conato revolucionario de Jauja, sin recalcar siempre con idéntico énfasis que ésta es sólo el subproducto de la historia primera y fundamental: la de un escritor que va construyendo una novela sobre ese conato revolucionario, basándose en notas, entrevistas, recuerdos y, sobre todo, en su capacidad de revolver, transformar e inventar.

Cuando se las lee desgajadas del conjunto de supuestos teóricos explícitos e implícitos en que Vargas Llosa apoya su arte de

${ }^{3}$ A. M. Gazzolo, "Historia de Mayta" en El Comercio, Lima, 9 de diciembre de 1984 .

${ }^{4}$ A. CORNEJO POLAR, "La historia como apocalipsis", Quehacer, Lima, 33 (1985), 76-86 (esp. pp. 77, 81 y 86). 
"mentir con conocimiento de causa", algunas de sus afirmaciones públicas pueden confundir:

En esta novela he tratado de expresar, desde un punto de vista histórico, el significado psicológico, moral e individual, de un fenómeno como el de "Sendero Luminoso"s.

Prefería escribir una novela sobre la insurrección de Jauja, porque la ficción tiene más fuerza que el ensayo[...]. La ficción es siempre más persuasiva, más ilustrativa, incluso, para narrar la raíz de un problema tan real como es la violencia política ${ }^{6}$.

Eso es lo que quisiera, al menos en mi novela, que quedara claro: que la violencia a partir de cierto momento carece ya de ideología ${ }^{7}$.

Tal vez para evitar un amor a la precisión que al gran público podría resultarle pedảnte, Vargas Llosa no ha insistido lo suficiente en que el tema de su novela es la elaboración de una novela sobre la insurrección de Jauja. Para quienes ven el producto final de esta empresa desde el punto de vista de su ideología subyacente - que nadie pretenderá negar, pues sería desconocer un componente ineludible de toda obra literaria - su carácter derivado o metadiegético, para decirlo en términos de Genette ${ }^{8}$, es un rasgo más bien irrelevante o, incluso, un medio no muy astuto de eludir el compromiso ideológico. Según este punto de vista, se insiste tanto en el carácter ficcional de casi todo lo que se narra, con el propósito de crear la sensación de que el mensaje serio que todo autor transmite a través de sus ficciones -en este caso la interpretación de la realidad peruana- es aquí una ficción más.

A la luz de las afirmaciones enteramente "ideológicas" de Vargas Llosa sobre su novela y, en general, de sus declaraciones públicas sobre problemas políticos nacionales e internacionales, resulta evidente lo gratuito de semejante hipótesis. En su obra narrativa

${ }^{5}$ Declaraciones en la Universidad Autónoma de Madrid, según Hoy, Lima, 31 de octubre de 1984.

${ }^{6}$ Declaraciones al diario $A B C$, Madrid, según La Industria, Trujillo, 2 de noviembre de 1984 y Expreso, Lima, 1o. de noviembre de 1984.

${ }^{7}$ Declaraciones a la revista Caretas, Lima, 1984, núm. 826, p. 31.

${ }^{8}$ Este término (al igual que algunos de los que utilizo más adelante y de los que no he podido prescindir por cuanto designan categorías bien delimitadas y ya familiares en los estudios de narratología) procede de G. GENETTE, "Discours du récit. Essai de méthode", en Figures III, Éds. du Seuil, Paris, 1972, pp. 67-282. Véase también, del mismo autor, Nouveau discours du récit, Éds. du Seuil, Paris, 1983. 
y teatral de los últimos años, el juego con las máscaras, la confrontación de papeles reales y ficticios, la mezcla libérrima de autobiografía y fantasía, no son un burdo instrumento para infiltrar ideas sino la realización de un ideal poetológico que se ha ido articulando cada vez con mayor nitidez a lo largo de su producción ensayística (especialmente en sus estudios sobre García Márquez y Flaubert), y que en un artículo escrito en 1982 sobre Los miserables de Víctor Hugo alcanza una notable consistencia teórica ${ }^{9}$. En este trabajo, la reflexión sobre un arte de novelar enteramente inconsciente de su propio artificio (en el que el autor no se sabe distinto del narrador y en el que éste a su vez se comporta como un sabelotodo y un charlatán irrestañable) está hecha desde una actitud de simpatía e incluso de nostalgia admirativa (como si el creador, hiperconsciente de su oficio, añorara la experiencia de lectura del jovencito fascinado por la voz tonante de un gran narrador-titiritero). Este homenaje a la última gran novela "clásica" va acompañado, sin embargo, por el reconocimiento - ya expresado antes en diversas ocasiones- de que Madame Bovary, publicada por Flaubert seis años antes que Los miserables, impone triunfalmente una nueva poética narrativa, vigente hasta nuestros días, que vuelve definitivamente obsoleto el estilo narrativo autoritario y grandilocuente:

Flaubert fue el primer novelista en plantearse como un problema central de la estructura novelística la presencia del narrador, el primero en advertir que éste no era el autor sino el más ambiguo de los personajes que el autor de una novela crea. Él volvió impersonal - es decir invisible - al narrador, algo que, desde entonces, han hecho la mayoría de los novelistas. Volverlo invisible no quiere decir suprimirlo, sino tornarlo astuto, calculador, escurridizo, tramposo: disolverlo en lo narrado mediante ciertas técnicas ${ }^{10}$.

Cualquiera se sentiría tentado de completar la idea diciendo: un narrador como el de casi todas las novelas de Vargas Llosa (excepción hecha de la autobiografía ficcional La tía Julia y el escribidor y de los pasajes de La ciudady los perros ocupados por los soliloquios de los personajes). Este narrador que se finge ausente, cuya única señal de existencia es una voz impersonal y anónima, siempre dispuesta a confundirse con las voces de los personajes y a modular vivencias ajenas, se ha convertido en un rasgo tan carac-

${ }^{9}$ M. VARGAS Llosa, "El último clásico. A propósito de Los miserables", Quimera. Revista de literatura, Barcelona, 30 (1983), 50-57.

${ }^{10}$ Ibid., p. 56. 
terístico de Vargas Llosa, que ha condicionado en sus lectores una disposición y unas expectativas incompatibles con las que promueve Historia de Mayta. Esto explicaría en buena parte la sorpresa, y aun el disgusto, que han experimentado algunos críticos al confrontarse con ella. En una rápida y bastante afectiva evaluación hecha bajo el impacto de la lectura reciente, uno de ellos formula una serie de reproches - y de elogios a obras anterioresque parecerían abonar mi hipótesis:

El problema de esta última (Historia de Mayta) es que el narrador no se contenta con describir los resultados de su investigación [...] sino que continuamente opina, juzga, pretende explicar las razones de por qué le interesa la empresa "descabellada" de Mayta, de por qué mienten sus informantes y de por qué el Perú se encuentra como está [...]. Compárese con la fuerza connotativa de Conversación... y La guerra... (por no citar La casa verde y Los cachorros, obras sin alter ego narrativo), en donde ni Zavaleta ni el periodista interfieren para que el lector responda a las interrogantes de por qué está jodido el Perú o por qué ocurrió lo de Canudos, respectivamente ${ }^{11}$.

De otro lado, la frecuente confusión de voz y focalización ${ }^{12}$ lleva a algunos a suponer que La ciudad y los perros, Conversación en la catedral o La guerra del fin del mundo representarían mejores aplicaciones de la técnica de un alter ego narrativo ${ }^{13}$, a pesar de que en todas ellas la voz primaria emana de una instancia tan poco visible como en las demás obras. Desde esta perspectiva - y contra lo que sus mismos detractores suponen- el narrador de Historia de Mayta no es imperfecto sino novedoso. Ni el "poeta" de La ciudad y los perros, ni Zavalita de Conversación en la catedral, ni el periodista miope de La guerra del fin del mundo, pertenecen a su género, a pesar de que, como personajes, puedan ser portadores de ciertas características psicosociales y cierta cosmovisión atribuibles al autor. La diferencia básica estriba en que ninguno de ellos cuenta la novela de la que forma parte ni, valga la redundancia, puede ser consciente de contarla. El "poeta" es el único del que es lícito decir que narra, pero no se lo puede identificar con la fuente primaria del discurso narrativo que engloba sus propios soliloquios.

11 R. GONZÁleZ VIGIL, "Vargas Llosa: El realismo en crisis", El Comercio, Lima, 25 de noviembre de 1984, p. 20.

12 Una detallada presentación crítica de estas dos categorías, procedentes de Genette, se hallará en S. REISZ DE RIVAROLA, "Voces y conciencias en el relato literario-ficcional", $L L L, 1983$, núm. 2, 187-218. p. 82

${ }^{13}$ Cf. R. GonzÁlez Vigil, loc. cit., y A. Cornejo POlaR, art. cit., 
Para decirlo en la nomenclatura de Genette, ninguno de ellos es el narrador extradiegético. El Varguitas de La tía Julia sí lo es. Por esta razón, y por el hecho adicional de que trata de hacernos creer que es el propio Vargas Llosa y de que mezcla en su relato autobiográfico datos reales y fantaseados, constituye el más cercano antecedente del escritor de Historia de Mayta. Éste no lleva la evidencia del nombre propio pero, a semejanza de Varguitas, tiene la misma costumbre del autor - corre, como él, todas las mañanas a la orilla del mar- y hasta parece vivir en su casa de Barranco. Otro rasgo que vincula a ambas novelas es la tematización de la ficción literaria en el interior de la ficción. Pero en La tía Julia esto ocurre de modo implícito, a través de la parodia del género de la literatura trivial en los extensos fragmentos ocupados por las historias cada vez más delirantes del autor de radionovelas Pedro Camacho (quien a su vez es un personaje del relato autobiográfico). La gran novedad de Historia de Mayta es que esa tematización se hace explícita y adquiere un rol protagónico. A diferencia de Varguitas, quien cuenta sus experiencias como quien habla, sin preocuparse por problemas de escritura, el narrador de Historia de Mayta reflexiona constantemente sobre su actividad específica, sobre la novela que pretende escribir, sobre la que está escribiendo en el acto mismo de pretender escribirla y, en general, sobre el arte de escribir ficciones realistas, capaces de envolver al lector en la ilusión y de suspender su incredulidad.

Este narrador que no cesa de hablar de sí mismo en tanto tal, que no cesa de opinar, de conjeturar y de esforzarse por mostrarle a su narratario ${ }^{14}$-evidente conocedor de novelas - los mecanismos en que se apoya su arte, resulta para muchos una presencia importuna: "en no menos de treinta ocasiones fatiga al lector explicándole que lo que está leyendo es una novela, por supuesto hecha de ficciones", apunta uno de los críticos que no aprecian esta modalidad narrativa de casi tan vieja data como el género ${ }^{15}$, pero que en Vargas Llosa significa un sustancial cambio de rumbo: un compromiso entre la objetividad de su admirado Flaubert y la verborragia subjetivísima del "último clásico".

La afirmación inicial del artículo sobre Víctor Hugo mencionado más arriba podría parecer a muchos perfectamente aplicable a Historia de Mayta:

${ }^{14}$ El término y la categoría correspondiente proceden de G. PRINCE, "Introduction à l'étude du narrataire", Poétique, 1973, núm. 14, 178-196.

15 A. Cornejo POlAR, art. cit., p. 77. 
El personaje principal de Los Miserables no es Monseñor Bienvenu, ni Jean Valjean, ni Fantine, ni Gavroche, ni Marius ni Cosette, sino quien los cuenta y los inventa, ese narrador lenguaraz que está continuamente asomando entre sus criaturas y el lector. Presencia constante, abrumadora, pertinaz, a cada paso interrumpe el relato para opinar, a veces en primera persona y con un nombre que quiere hacernos creer es el del propio Víctor Hugo ${ }^{16}$.

Y, en efecto, el personaje principal de Historia de Mayta no es Mayta, ni Vallejos, ni sus camaradas revolucionarios, sino el narra dor que entrevista a los parientes y amigos para reconstruir lo sucedido y escribir a partir de esos datos una novela. El espesor de su presencia y su locuacidad no están muy lejos de las cualidades que ostenta el alter ego de Víctor Hugo. Para comprobarlo, bastará recordar algunos de los muchos pasajes en los que manifiesta sus opiniones, sus intereses, sus expectativas y sus conjeturas sobre los personajes y los hechos narrados:

"Este muchacho dará que hablar", decía el Padre Giovanni. Sí, dio que hablar, pero no en el sentido que usted creía, Padre ( $p$ 16).

¿Por qué Mayta? Si de él no se acuerda nadie. En efecto ¿por qué? ¿Porque su caso fue el primero de una serie que marcaría una época? ¿Porque fue el más absurdo? ¿Porque fue el más trágico? $¿$ Porque en su absurdidad y tragedia, fue premonitorio? $¿ \mathrm{O}$, simplemente, porque su persona y su historia tienen para mí algo invenciblemente conmovedor, algo que, por encima de sus implicaciones políticas y morales, es como una radiografía de la infelicidad peruana? (p. 21).

Tal vez tiene razón, tal vez sea por el carácter precursor de aquella aventura. Es verdad, ella inauguró una época en el Perú, algo que ni Mayta ni Vallejos pudieron adivinar en ese momento. Pero también es posible que todo ese contexto histórico no tenga otra importancia que la de un decorado y que el elemento oscuramente sugestivo en ella, para mí, sean los ingredientes de truculencia, marginalidad, rebeldía, delirio, exceso, que confluyen en aquel episodio que protagonizó mi condiscípulo salesiano (p. 53).

Queda meditabundo, sopesando las extravagancias de la historia. Lo dejo reflexionar sin apremiarlo, seguro de que aún no ha concluido. ¿El abnegado Mayta convertido en monstruo bifronte,

16 M. VARGaS LlOSA, art. cit., p. 50. 
urdiendo una arriesgadísima conspiración para tender una trampa a sus camaradas? Es demasiado truculento: imposible de justificar en una novela que no adopte, de entrada, la irrealidad del género policial (p. 102).

Le aclaro que todos los testimonios que consigo, ciertos o falsos, me sirven. ¿Le pareció que desecharía sus informaciones? Se equivoca; lo que uso no es la veracidad de los testimonios sino su poder de sugestión y de invención, su color, su fuerza dramática. Eso sí, tengo el pálpito de que sabe más de lo que ha dicho (pp. 114-115).

Si las noticias son ciertas y la guerra se generaliza, apenas dispondré de tiempo para terminar mi novela; si la guerra llega a las calles de Lima y a la puerta de mi casa dudo que ello sea ya posible (p. 167).

Anhelaba, en esa última conversación, algo espectacular, dramático, que arrojara una luz conflictiva sobre lo que sentía y soñaba Mayta en vísperas del alzamiento (p. 210).

Acaso el encuentro con el Mayta de carne y hueso en lugar de ayudarme estropearía lo que llevo haciendo (p. 317).

¿Habladuría; pose? No. Sus recuerdos son vacilantes, y, a menudo, errados. Debo rectificarlo a cada paso. Me asombra, porque, todo este año, obsesionado con el tema, suponía ingenuamente que el protagonista también lo estaba y que su memoria seguía escarbando en lo ocurrido en aquellas horas, un cuarto de siglo atrás. ¿Por qué hubiera sido así? Aquello fue para Mayta un episodio en una vida en la que, antes y después, hubo muchos otros, tanto o acaso más graves. Es normal que éstos desplazaran o empobrecieran a aquél (pp. 329-330).

Tampoco faltan pasajes en los que se abren paso opiniones teñidas de afectividad sobre la realidad circundante y sobre personalidades de la política y las letras, como Ernesto Cardenal:

Son feas estas casas, imitaciones de imitaciones, a las que el miedo asfixia de rejas, muros, sirenas y reflectores. Las antenas de la televisión forman un bosque espectral. Son feas estas basuras que se acumulan detrás del bordillo del Malecón y se desparraman por el acantilado. ¿Qué ha hecho que en este lugar de la ciudad, el de mejor vista, surjan muladares? La desidia. ¿Por qué no prohiben los dueños que sus sirvientes arrojen las inmundicias prácticamente bajo sus narices? Porque saben que entonces las arrojarían los sirvientes 
de los vecinos, o los jardineros del Parque de Barranco, y hasta los hombres del camión de la basura, a quienes veo, mientras corro, vaciando en las laderas del acantilado los cubos de desperdicios que deberían llevarse al relleno municipal. Por eso se han resignado a los gallinazos, los ratones y la hediondez de estos basurales (pp. 7-8).

Aún conservo viva la impresión de insinceridad e histrionismo que me dio. Desde entonces, evito conocer a los escritores que me gustan para que no me pase con ellos lo que con el poeta Cardenal, al que, cada vez que intento leer, del texto mismo se levanta, como un ácido que lo degrada, el recuerdo del hombre que lo escribió (p. 92).

Pero los más característicos de su estilo son aquéllos en los que el narrador-novelista expresa sus concepciones acerca del género literario que él mismo intenta cultivar y del método de trabajo que él estima adecuado para ello:

- Porque soy realista, en mis novelas trato siempre de mentir con conocimiento de causa - le explico. Es mi método de trabajo. $\mathrm{Y}$, creo, la única manera de escribir historias a partir de la historia con mayúsculas (p. 77).

Los apuntes son lo de menos. Lo que no queda en la memoria, no sirve para la novela (p. 89).

Mi obligación es escuchar, observar, cotejar las versiones, amasarlo todo y fantasear (p. 140).

Le aclaro-: En una novela siempre hay más mentiras que verdades, una novela no es nunca una historia fiel. Esa investigación, esas entrevistas, no eran para contar lo que pasó realmente en Jauja, sino, más bien, para mentir sabiendo sobre qué mentía (p. 320).

Los últimos ejemplos ponen en evidencia que la semejanza con el narrador de Los miserables es algo engañosa. Una vez más, la reflexión literaria del propio Vargas Llosa puede ayudar a percibir la diferencia específica. Después de afirmar que la invención primera y fundamental de un novelista es siempre el narrador y que, por lo mismo, no se lo debe identificar con el autor ni aun cuando lleve su nombre, hace una observación muy iluminadora:

Cada novelista inventa un narrador dotándolo de una naturaleza particular, de unas facultades y limitaciones precisas, en función de lo que quiere contar. Esta operación -inventar a alguien 
que narre lo que uno quiere narrar- es acaso la más importante que realiza el novelista y sin embargo, hasta hace relativamente poco tiempo los novelistas ni siquiera lo sabían y, como el Víctor Hugo que escribió Los miserables, la llevaban a cabo de una manera intuitiva o mecánica.

Si hay algo que distingue al novelista clásico del moderno es precisamente el problema del narrador. La inconsciencia o la consciencia con que lo aborda y lo resuelve establece una línea fronteriza nítida entre el novelista antiguo y el contemporáneo ${ }^{17}$.

En su última novela, Vargas Llosa ha inventado un narrador tan parecido a él que incita a la identificación contra la que él alerta en sus escritos teóricos. Sin embargo, el parecido no es, como en Víctor Hugo, el producto espontáneo de la confusión de un autor que se cree el narrador. La invención de Vargas Llosa no cumple tan sólo la función de narrar lo que él quería narrar - los sucesos de Jauja - sino, a la vez, la de contar el proceso de elaboración de lo narrado y, en general, la de presentar de un modo directo y vívido los principales problemas que él debe enfrentar al construir sus novelas. El parecido es, pues, un medio eficaz de predisponer al lector a integrar de modo natural, en la recepción de la historia del conato subversivo de Jauja, una temática literaria que constantemente lo aparta de la ficción para obligarlo a pensar en sus leyes. Es perfectamente lógico - verosímil- que el narrador de una historia que se exhibe ostentosamente como ficcional sea un novelista y que el novelista dé la sensación de ser el propio Vargas Llosa. ¿Quién con más autoridad que él podría hablar de su actividad fabuladora? Pero el procedimiento seguido aquí es casi el invẹrso del de Los miserables: en lugar de dejar que su alter ego hable -o escriba- desde un espacio aparentemente exterior a la ficción, Vargas Llosa lo introduce tanto en la historia de Mayta (de quien lo hace compañero de estudios) como en la historia primaria de la que aquélla es resultado, la de la indagación en torno a los sucesos narrados y, en especial, la de las entrevistas a allegados de los dos actores principales, Mayta y Vallejos. De este modo, al hacerlo doblemente homodiegético (vuelvo a usar un término consagrado por Genette) elude la dificultad que le habría planteado un narrador a la vez demasiado perceptible y ajeno a la historia, que en virtud de estos rasgos diera la sensación de manipular su material desde afuera y desde arriba, como un arrogante titiritero. Semejante combinación está excluida de su poética, como surge del siguiente comentario: "Sucede que en una novela

${ }^{17}$ Ibid., p. 56. 
moderna, salvo en los casos en que se trata de un narradorpersonaje, el narrador es un dato escondido, él mismo una ausencia, un sobreentendido"'18.

Un narrador que habla de sí mismo y que expresa abiertamente sus opiniones y sentimientos sólo es tolerable, desde estos postulados estéticus, cuando forma parte del mundo que se instaura miméticamente en la ficción. Y, en consecuencia, cuando posee facultades análogas a las de los demás personajes y está sujeto, como ellos, a limitaciones epistémicas. La omnisciencia queda así sustituida por la capacidad de ver, recordar, conjeturar y fantasear. Dentro de las mismas normas, un narrador que hace reflexiones metaliterarias y metanarrativas, sólo es aceptable si es personaje y si, como tal, se ajusta a la figura de un escritor. Cuando no se sigue el precepto de la "invisibilidad" flaubertiana, no parece quedar más opción que la de un narrador homodiegético, con las estrechas posibilidades cognoscitivas de una conciencia humana real.

Veamos si Vargas Llosa cumple con estos postulados realistas. Un rápido recorrido por el primer capítulo permite reconocer ya las modalidades narrativas puestas en práctica a lo largo de toda la novela. Como ha sido observado de inmediato por los críticos, el relato se desarrolla en dos niveles: 1) un presente, en el que el narrador conversa con los allegados de Mayta y de Vallejos para enterarse de las circunstancias exactas de la insurrección y de las motivaciones de su principal actor y 2) un pasado, en el que tienen lugar los sucesos investigados. Se trata de dos historias conectadas por una relación de subordinación: la historia del nivel 1) produce la del nivel 2) y, en consecuencia, esta última aparece incluida en aquélla. Aunque a primera vista no parezca evidente, ambas historias son relatadas por el mismo narrador, el alter ego de Vargas Llosa, que se propone escribir - y que va escribiendo a medida que avanza en su indagación- la historia de Mayta. Hay que aclarar, empero, que si bien la identidad personal no varía - siempre se trata del escritor-, cambian sustancialmente su posición y su "sabiduría" en relación con lo narrado.

En el primer nivel cuenta lo que él está viviendo en la forma característica de la narración simultánea (otro término acuñado por Genette). Puesto que él se mantiene aquí siempre presente, como primer actor cuando él mismo piensa o recuerda, o como segundo actor cuando entrevista a los testigos, su condición homodiegética le permite hablar mucho de sí mismo y de los demás, así como

18 Ibid., p. 54 
dar toda clase de opiniones y valoraciones personales; pero, como contrapartida, no puede introducirse en la conciencia de los personajes que pertenecen, como él, al primer nivel diegético.

En conformidad con una elemental exigencia realista, él no puede saber lo que piensa la tía de Mayta (o cualquiera de sus entrevistados) excepto por lo que ella misma le diga o por lo que él pueda conjeturar a partir de sus gestos. Como en la vida real, en su condición de personaje sólo puede conocer su propia interioridad. Un buen ejemplo de su locuacidad es el comienzo de su novela, en el que describe su carrera matinal por el malecón de Barranco en el momento mismo en que está corriendo. La ilusión de que su discurso es simultáneo con su carrera es una de las tantas "fantasías irrealistas" de las que, como ha señalado acertadamente F. Martínez-Bonati ${ }^{19}$, hace amplio uso la moderna narrativa realista. Ella sirve para presentar a través de su mirada el espectáculo de esa parte de la ciudad y para entremezclar, en esa imagen panorámica captada por su conciencia, sus sentimientos, opiniones y recuerdos. La escena se cierra con la indicación expresa de que sus palabras coinciden con sus acciones y dan forma visible a sus pensamientos:

He terminado de correr. Veinte minutos de ida y vuelta entre el Parque Salazar y mi casa es decoroso. Además, mientras corría, he conseguido olvidar que estaba corriendo y he resucitado las clases en el Salesiano y la cara seriota de Mayta, sus andares bamboleantes y su voz de pito. Está ahí, lo veo, lo oigo y lo seguiré viendo y oyendo mientras se normaliza mi respiración, hojeo el periódico, desayuno, me ducho y comienzo a trabajar (p. 10).

La narración simultánea de sus actividades prosigue luego con la rápida caminata por los viejos barrios de Mayta y la visita a la tía, doña Josefa Arrisueño. Desde antes de su entrevista con ella y luego, a lo largo de la conversación, se intercalan escenas de la vida de Mayta: de su infancia y de su encuentro con Vallejos. Algunas de ellas aparecen claramente como recordadas o imaginadas por el narrador. Un ejemplo de directa evocación:

Todavía recuerdo la dureza con que habló de ellos, en esa última conversación, en la plaza San Martín. No servían para gran cosa, según él:

- Los de este país al menos - precisó-. Se sensualizan muy rápido, no tienen convicciones sólidas. Su moral vale apenas lo que

19 “"El acto de escribir ficciones", Dispositio, 3 (1978), 137-144. 
un pasaje de avión a un Congreso de la Juventud, de la Paz, etc. (pp. 27-28).

Mientras camina por los barrios de Mayta y piensa en la noche en que éste conoció a Vallejos - antes de que la tía le dé un testimonio directo- proporciona, en cambio, un ejemplo muy evidente de fabulación ${ }^{20}$. De la observación del contorno y una conjetura sobre Mayta pasa sin solución de continuidad a referir sentimientos de este último que él jamás pudo conocer:

Nada de eso se ve, mientras camino por el Jirón Dante hacia su encuentro con el Jirón González Prada, como debió hacerlo Mayta aquella noche, para llegar a casa de su tía-madrina, si es que vino en ómnibus, colectivo o tranvía, pues en 1958 todavía traqueteaban los tranvías por donde ruedan ahora, veloces, los autos del Zanjón. Estaba cansado, aturdido, con un leve zumbido en las sienes y unas ganas enormes de meter los pies en el lavador de agua fría. No había mejor remedio contra la fatiga del cuerpo o del ánimo: esa sensación fresca y líquida en las plantas, el empeine y los dedos de los pies sacudía el cansancio, el desánimo, el malhumor, levantaba la moral (p. 12).

La mayoría de esa escenas del pasado tiene, sin embargo, un estatuto ambiguo. Su motivación epistémica ${ }^{21}$ - la respuesta a la pregunta ¿de dónde se sabe esto? - aparece oscurecida por el hecho de que su relación genética con lo que se conversa a lo largo de la entrevista queda inexpresada. La conexión entre los dos niveles se produce, por lo común, mediante alguna redundancia léxica o temática (repetición de una palabra o de una unidad semántica mayor) o mediante una aparente respuesta o un aparente comentario a una pregunta o aseveración del nivel diegético precedente. He aquí dos ejemplos característicos:

${ }^{20}$ Fuera del primer capítulo, tal vez el más llamativo caso de invención presentado como tal sea el episodio del cap. 4, en que el narrador visita el Museo de la Inquisición y, a la vez, fantasea una visita de Mayta al mismo museo. El final de la escena hace explícito el carácter imaginario de las reflexiones de Mayta: "Y entiendo por qué Mayta me ha acompañado obsesivamente en el recorrido del Museo" (p. 124).

${ }^{21}$ Sobre esta noción véase M. RoN, "Free Indirect Discourse, Mimetic Language Grmes and the Subject of the Fiction", Poetics Today, 2 (1981), 17 39; y J. L. RIVAROLA y S. REISZ DE RIVAROLA, "Semiótica del discurso referido", $H A M B$, pp. 163-173. 
Nivel primero (entrevista)

Nivel segundo (encuentro de Mayta con Vallejos)

Nivel segundo

Nivel primero
Pero esa noche se quedó hasta el último, habla que habla con Vallejos, en ese rincón. Habrán pasado como veinticinco años y me acuerdo como si fuera ayer. La revolución para aquí, la revolución para allá. Toda la santa noche.

¿La revolución? Mayta se volvió a mirarlo. ¿Había hablado el muchacho o el viejo en zapatillas? (p. 16)

-O sea que hablas franchute - hizo una morisqueta Vallejos-. ¿Dónde lo aprendiste?

-Solito, con un diccionario y un libro de idiomas que se ganó en una tómbola - me cuenta doña Josefa (p. 22).

Como puede apreciarse, semejante tipo de conexión, que yo me atrevería a bautizar como "pseudodialógica" (pues se crea la falsa sensación de que personajes ubicados en distintos niveles dialogan entre sí), deja deliberadamente en la nebulosa el proceso de generación del segundo nivel a partir del primero. No se puede decidir, en efecto, si las escenas de la fiesta en que. Mayta conoce a Vallejos $-\mathrm{y}$ todas las similares a ellas - son versiones "cinematográficas" de lo que cuenta la entrevistada (con esa minucia que sólo puede tener un registro audiovisual) o son fabulaciones del narrador a partir de lo que oye.

Cuando al avanzar en la lectura nos enteramos de que todo eso es la novela, la última de estas conjeturas se nos impone como la más natural: cada una de las escenas de la vida de Mayta es el producto de la actividad imaginaria del narrador, sobre la base de los testimonios que ha recogido. Pero aun con esta certidumbre, el narratario de esta novela, y con él nosotros, los lectores, no podremos saber jamás cuánto del diálogo del primer nivel ha ingresado en la fabulación del segundo nivel. En este punto de la reflexión no serviría mucho recordar que, como al final de cuentas todo es ficcional (tanto la entrevista supuestamente "real" comola historia supuestamente "imaginaria" de Mayta), no vale la pena plantearse semejantes preguntas. Recurrir a este expediente puede resultar seductor, pero implicaría una simplificación peligrosa, ya que llevaría a desconocer que en el interior de esa gran ficción que es la novela, la condición ineludible para que el concepto mismo de "ficción" se incorpore a ella como tema es que ciertos 
elementos se acepten como reales. El narrador y sus entrevistados se presentan como "reales", sus diálogos también. Los diálogos de Mayta y Vallejos, en cambio, son fabulaciones construidas con algunos elementos "reales" indeterminables. La indeterminación tiene, en un caso como éste, un valor semiótico muy particular: alude a la naturaleza de toda ficción, que cambia y transforma elementos de la realidad pero que nunca delata la exacta proporción de sus mezclas. El hecho de que el narrador no especifique cuál es la relación entre sus relatos de la vida de Mayta y lo que sus entrevistados le cuentan representa, a mi entender, un implícito enunciado metaliterario que podría glosar como sigue: "estos relatos son, como todas las novelas del autor Vargas Llosa, una amalgama, indiscernible para el lector, de hechos y objetos fácticos (vividos u observados por él) y de hechos y objetos meramente posibles, producto de su fantasía". Puesto que semejante combinación es la típica de las ficciones realistas, en oposición a las ficciones fantásticas o maravillosas ${ }^{22}$, en el trasfondo de las preferencias literarias reiteradamente manifestadas por Vargas Llosa, ese enunciado implícito adquiere una connotación poetológica: "los relatos de la vida de Mayta son realizaciones paradigmáticas del código estético en que se basa toda la obra de Vargas Llosa".

Como señalé más arriba, la posición y la "sabiduría" del narrador respecto de lo narrado se modifican sustancialmente al pasar de un nivel a otro. Después de haber reconocido el estatuto "real" del primer nivel y el "imaginario" del segundo, la explicación de la diferencia surge naturalmente. En el primer nivel el narrador es homodiegético, aparece como actor de la historia que cuenta, y en tanto personaje "real" sólo puede conocer sus propios pensamientos. Ello lo autoriza a hablar mucho de su propia interioridad y a expresar toda clase de opiniones y de valoraciones pero, a la vez, le impide saber con certeza lo que los otros personajes "reales" sienten o piensan. Puesto que la directa presentación de los estados de ánimo ajenos atentaría contra el verosímil propuesto desde un comienzo, es reemplazada por conjeturas y por la descripción de gestos y actitudes, es decir, de lo "realmente" perceptible. He aquí dos muestras:

Mientras habla, me examina, disimulando apenas su curiosidad. Tiene una voz con gallos, parecida a la de Mayta, unas manos

${ }^{22}$ S. REISZ DE RIVAROLA "Ficcionalidad, referencia, tipos de ficción literaria", LLL, 1979, núm. 2, 144-164. 
como tamales, y, aunque sonría a veces, ojos tristes y aguanosos. Se queja de la vida que sube, de los atracos callejeros (p. 15).

Pasa una mirada tristona por el cuarto sin gente, como reponiendo en esas sillas, rincones, ventanas, a los parientes y amigos que venían a cantarle Happy Birthday, a festejar su buena mano para la cocina, y suspira. Ahora sí parece de setenta años (p. 27).

Recordemos los preceptos tan claramente formulados por el propio Vargas Llosa: un narrador que se hace ver y habla mucho, sólo es admisible si a la vez es personaje de la historia que narra y si como tal - añado por mi parte - tiene las mismas limitaciones epistémicas de un ser humano.

¿Qué ocurre, en cambio, con ese narrador "invisible" consagrado por Flaubert y elevado por Vargas Llosa a la categoría de procedimiento arquetípico de la moderna narrativa realista? Este narrador "totalmente inmerso y disuelto en lo narrado" ${ }^{23}$, se diferencia del narrador-personaje por su capacidad de ingresar en las conciencias de todos sus personajes. Es ésta otra de las "fantasías irrealistas" que crean, en la novelística contemporánea, la ilusión de realidad: la única limitación de semejante narrador es la que temporariamente le impone su instalación en una conciencia dada. Cuando se adueña de la vida interior de un personaje, sólo puede ver a través de sus ojos, pero siempre dispone de la libertad de desplazarse de una conciencia a otra o, incluso, de ubicarse fuera de toda conciencia, a la manera de una cámara que sólo registra los datos externos. La diferencia entre este tipo de narrador (que experimenta mucho más de lo que un ser humano podría experimentar) y el narrador omnisciente de la novela "clásica" es que éste último no "observa" ni "capta" ni "coexperimenta" lo que el personaje siente y piensa, sino sencillamente lo "sabe" a la manera divina, independientemente de toda actividad perceptiva o sensitiva, y lo cuenta en el mismo estilo que utiliza para referir hechos externos.

Después de lo dicho, resulta claro que, en el segundo nivel, el narrador-escritor de Historia de Mayta adopta la modalidad de esa instancia a la vez "invisible" y camaleónica, que nunca habla de sí misma, cuya voz sólo refiere hechos y vivencias ajenas y que es capaz de adentrarse en las conciencias de los personajes y de identificarse alternativamente con cada uno de ellos. Éste es, precisamente, el tipo de narrador que Vargas Llosa ha utilizado en la mayoría de sus novelas y que, por ello mismo, ha consagrado

${ }^{23}$ M. VARGaS LlOSA, art. cit., p. 52. 
como marca de su estilo. Los críticos a quienes les desagradan las "intromisiones" del narrador de Historia de Mayta, su verborrea y su peso "yoico", parecen olvidar o desconocer que el mismo narrador que frustra sus expectativas estéticas en el primer nivel las cumple cabalmente en el segundo. El primero es el nivel de la "teoría", el apropiado para hablar de la novela como género y como proyecto personal; el segundo es el nivel de la "praxis", el de la realización de los principios poetológicos expresados abiertamente en el primero y contenidos implícitamente en el segundo. Aparentemente, la novela de la que habla el narrador es la integrada por todos los pasajes del segundo nivel. Sin embargo, el capítulo final trae una instrucción de lectura que obliga a remodelar esa hipótesis. En la entrevista con el Mayta "real", el narrador le hace a su interlocutor una declaración que incide retroactivamente en la interpretación de los nueve capítulos precedentes:

Me gustaría conversar con usted - añado-. Hacerle algunas preguntas, aclarar ciertas cosas. Sólo lo que usted quiera y pueda contarme, desde luego. Tengo muchos enigmas dándome vueltas en la cabeza. Además esta conversación es mi último capítulo. No puede usted negármela, me dejaría la novela coja (pp. 321-322).

Si la conversación con Mayta es el último capítulo de la novela, todas las demás conversaciones con testigos también son la novela. La afirmación final parece corroborar esta idea:

Y recuerdo, entonces, que hace un año comencé a fabular esta historia mencionando, como la termino, las basuras que van invadiendo los barrios de la capital del Perú (p. 346).

En el último momento de la lectura, las palabras del alter ego de Vargas Llosa nos obligan a repensar su estatuto. Si también las entrevistas han sido fabuladas sobre la base de ciertas realidades indeterminables, entonces su propia condición de narradorpersonaje se revela como ficticia: su presencia en los diálogos es tan imaginaria como la de los supuestos entrevistados. ¿Se nos quiere sugerir de esta manera que quien habla al final es el propio Vargas Llosa? La tentación de aceptar esta hipótesis es bastante fuerte. Sin embargo, el sutil enlace del discurso final con el inicial impide hacerlo: la última frase remite, casi a la manera de una cita, al comienzo del relato, en el que alguien parecido a Vargas Llosa observa la basura y recuerda a su "compañero de colegio" Mayta, dato que en ese mismo capítulo es desenmascarado como una invención, al igual que la homosexualidad de 
Mayta y el Perú apocalíptico - destrozado por el terrorismo, invadido por cubanos y marines - en el que se desarrollan las entrevistas. ¿Mentía el narrador al comienzo? ¿Dice la verdad al final? La oposición entre mentira y verdad queda neutralizada por la noción de fabulación.

La última frase de la novela trae un golpe de efecto similar al de la revelación del relato policial con enigma: la inesperada declaración "hace un año comencé a fabular esta historia" (en la que esta se refiere de modo global a todo el discurso narrativo) cambia a posteriori el estatuto de todo lo narrado: la relación entre un primer nivel "real" y un segundo nivel "imaginario"' generado por aquél se muestra, a su vez, imaginaria. El narrador no se ha entrevistado "realmente" con testigos para fantasear el pasado de Mayta y "mentir con conocimiento de causa". Ahora sabemos que ha fantaseado, que se ha entrevistado para poder fantasear a partir de las entrevistas imaginadas. Lo que él nos propone al final no es una ficción, sino una ficción de la ficción. ¿Y dónde queda él mismo? ¿Quién es él mismo? Puesto que no es el autor real de la novela sino la invención primera y fundamental del autor - alguien que narra lo que él quería narrar: una ficción sobre la ficción - también él es, por cierto, una criatura de ficción. Pero con decir esto no se agota la complejidad de su situación, su ambigüedad, su extraña ubicuidad en los diferentes mundos del relato.

Tal vez la más cabal manifestación de su naturaleza proteica se encuentre en aquellos pasajes del capítulo seis en que los juegos con la voz y la focalización cumplen la misión de superponer y fusionar parcialmente dos diálogos: el actual, entre Blacquer y el narrador, y el diálogo pasado - rememorado en el actual- entre el mismo Blacquer y Mayta:

¿Lo había entendido Blacquer? Su inmovilidad era de estatua, otra vez. Avanzando la cabeza, sintiendo que transpiraba, persiguiendo las palabras que el cansancio y la preocupación me escamoteaban, oyendo de cuando en cuando, en esos altos desconocidos, al niño y la mujer, se lo expliqué de nuevo (p. 172).

Quedé con la boca entreabierta, sin animarme a terminar, y, por primera vez desde el principio de la charla con Blacquer, vacilé. Tenía la cara llena de sudor, las pupilas dilatadas y las manos me temblaban. ¿Aventura y traición? (p. 173).

El primer pasaje es representativo de la manipulación de los pronombres: en el relato en tercer persona, que comienza con un 
discurso indirecto libre ${ }^{24}$, correspondiente al pensamiento de Mayta ("¿Lo había entendido Blacquer?"), se infiltra sin zonas de transición la primera persona ("me escamoteaban", "se lo expliqué de nuevo"). El segundo pasaje hace uso de un recurso algo más sofisticado y, por lo mismo, menos llamativo: el relato de Mayta en primera persona contiene una descripción de sí mismo que implica una focalización externa, es decir, la perspectiva del narrador o de otro personaje que observa a Mayta, ya que él mismo no puede percibir que sus pupilas están dilatadas.

En ambos casos, y en todos los similares a ellos, el escándalo epistemológico en que se funda la novela - la disolución de fronteras entre distintos mundos posibles- se muestra del modo más directo: la voz y la visión de las que nacen esos extraños enunciados son a la vez las del narrador "real", las del narrador "imaginario", las del Mayta "imaginario" y las del narrador que ha fabulado "esta historia".

SUSANA REISZ DE RIVAROLA

Pontificia Universidad Católica del Perú

${ }^{24}$ Sobre esta manera de referir discursos ajenos y otras variedades de “conjunciones discursivas" véase J. L. RIVAROLA y S. REISZ DE RIVAROLA, art. cit. 